\title{
Milrinone in heart failure Acute effects on left ventricular systolic function and myocardial metabolism
}

\author{
A D TIMMIS, P SMYTH, M MONAGHAN, L WALKER, K DALY, A A MCLEOD, \\ D E JEWITT
}

From the Department of Cardiology, King's College Hospital, London

\begin{abstract}
SUMMARY Milrinone, a new bipyridine compound related to amrinone, is a potent non-adrenergic inotrope in experimental preparations and also shows vasodilator activity. In the present study the haemodynamic and metabolic effects of milrinone were evaluated in 12 patients with congestive heart failure. Milrinone $5 \mathrm{mg}$ given orally produced a sharp reduction in left ventricular end diastolic pressure without significantly affecting stroke volume. The improvement in left ventricular function was due to a combination of vasodilatation and positive inotropism. Thus small reductions in blood pressure and systemic vascular resistance were associated with increments in the isovolumic indices of left ventricular function. The relation between left ventricular end systolic pressure and dimension was displaced leftwards and downwards. Only reductions in left ventricular cavity dimension were statistically significant, however. Though myocardial oxygen consumption did not change significantly, it tended to increase whereas lactate consumption tended to decrease.

This trend towards oxygen imbalance suggests the need for caution in the use of milrinone in patients with severe coronary artery disease.
\end{abstract}

Milrinone is a recently introduced derivative of amrinone. Both compounds share a bipyridine ring structure and increase the contractility of isolated heart muscle. ${ }^{1}$ The inotropic potency of milrinone, however, is $10-30$ times greater than that of its parent compound. ${ }^{2}$ The mechanism of this inotropic effect remains unclear. Milrinone is a potent inhibitor of cyclic adenosine monophosphate adenylic acid (AMP) phosphodiesterase, ${ }^{1}$ but peak increments in muscle tension precede maximal increase in intracellular cyclic AMP. ${ }^{2}$ Phosphodiesterase inhibition is unlikely, therefore, to account fully for the inotropic properties of the drug. In addition to its direct cardiac effects, milrinone also relaxes vascular smooth muscle in experimental preparations, though at considerably higher doses than are required to produce a positive inotropic response. ${ }^{2}$

Recent work has confirmed beneficial haemo-

Requests for reprints to Dr A D Timmis, Department of Cardiology, Guy's Hospital, London SE1 9RT.

Accepted for publication 19 March 1985 dynamic responses to milrinone in patients with congestive heart failure. ${ }^{3-5}$ The contributions that positive inotropism and vasodilatation make towards the clinical efficacy of the drug are, however, unknown. This question is important because the balance of these separate cardiovascular influences largely determines the effects of treatment on myocardial oxygen demand-a consideration of particular relevance in patients with coronary artery disease. ${ }^{6}$

In the present study, therefore, we measured haemodynamic and metabolic responses to milrinone in patients with congestive heart failure. In particular, we evaluated the effects of this agent on left ventricular systolic function-as determined by contractile performance and loading conditions-and myocardial oxygen consumption.

\section{Patients and methods}

PATIENT SELECTION

Twelve patients (10 men, two women; age range 31-64 (mean) 52.7 years) were studied (Table 1). All 
Table 1 Patient characteristics

\begin{tabular}{|c|c|c|c|c|c|c|}
\hline Case No & Sex/age (yr) & Diagnosis & NYHA class & $E F(\%)$ & $L V E D P(\operatorname{mm} H g)$ & Daily frusemide dosage ( $m g$ ) \\
\hline $\begin{array}{r}1 \\
2 \\
3 \\
4 \\
5 \\
6 \\
7 \\
8 \\
9 \\
10 \\
11 \\
12\end{array}$ & $\begin{array}{l}M / 39 \\
M / 55 \\
M / 45 \\
M / 54 \\
M / 64 \\
M / 58 \\
F / 50 \\
M / 31 \\
M / 60 \\
F / 59 \\
M / 53 \\
M / 64\end{array}$ & $\begin{array}{l}\text { CAD } \\
\text { CAD } \\
\text { CAD } \\
\text { CAD } \\
\text { CAD } \\
\text { CCM } \\
\text { CCM } \\
\text { CCM } \\
\text { CAD } \\
\text { CCM } \\
\text { CCM } \\
\text { CAD }\end{array}$ & $\begin{array}{l}\text { III } \\
\text { III } \\
\text { II } \\
\text { III } \\
\text { III } \\
\text { III } \\
\text { II } \\
\text { III } \\
\text { III } \\
\text { III } \\
\text { III } \\
\text { III }\end{array}$ & $\begin{array}{l}10 \\
27 \\
44 \\
13 \\
\text { NA } \\
19 \\
39 \\
22 \\
21 \\
\text { NA } \\
23 \\
10\end{array}$ & $\begin{array}{r}31 \\
16 \\
24 \\
23 \\
17 \\
28 \\
8 \\
14 \\
24 \\
25 \\
8 \\
15\end{array}$ & $\begin{array}{r}120 \\
250 \\
80 \\
80 \\
80 \\
240 \\
40 \\
40 \\
80 \\
160 \\
120 \\
120\end{array}$ \\
\hline
\end{tabular}

$\mathrm{CAD}$, coronary artery disease; CCM, congestive cardiomyopathy; EF, angiographic ejection fraction (not available (NA) in two cases); LVEDP, left ventricular end diastolic pressure (measured in the supine position).

were selected on the basis of moderate to severe congestive heart failure (New York Heart Association functional classes II and III) that had responded inadequately to conventional treatment. Ten patients had undergone diagnostic cardiac catheterisation within 12 months of the study. This had confirmed severely impaired left ventricular function with a mean (SEM) angiographic ejection fraction of only 23 (4)\%. Seven of the 10 patients had coronary artery disease by angiographic or clinical criteria and the remainder congestive cardiomyopathy of uncertain cause. The patients were all in stable sinus rhythm. Written informed consent was obtained from each patient before inclusion in the study, which had been approved by the hospital ethical committee.

\section{CARDIAC CATHETERISATION}

The patients were studied in the supine position after fasting. Premediction with diazepam 5-10 mg orally was given. Heparin $1000 \mathrm{IU} /$ hour was administered by continuous intravenous infusion for 12 hours before and during each study. All catheterisation procedures were performed under fluoroscopic control using up to $20 \mathrm{mg}$ of lignocaine local anaesthetic. A balloon tipped triple lumen thermodilution catheter (Edwards Laboratories Inc) was placed in the pulmonary artery. This permitted technically adequate right sided pressure measurements in all the patients except one, in whom baseline error made data interpretation impossible. In a second patient a satisfactory pulmonary capillary wedge pressure recording could not be obtained. The mean of at least four thermodilution cardiac output recordings was taken for each measure of cardiac output. Arterial pressure was monitored, and blood samples obtained, through the sidearm of a short sheath positioned in the femoral artery. A micromanometer tipped catheter (Millar Instruments Inc) was introduced through the femoral arterial sheath and positioned in the left ventricle for high fidelity pressure recordings. All pressures were measured with reference to the mid-chest and were recorded with an electrocardiogram on a Mingograph 82 recorder (Siemens Ltd). Coronary sinus cannulation with a dual thermistor catheter (Wilton Webster Ltd) was performed in 10 patients using the techniques described by Ganz et al. ${ }^{7}$ This permitted determination of coronary sinus flow by continuous thermodilution. Adequate coronary sinus blood sampling for metabolic measurements was possible in eight of these patients.

\section{ECHOCARDIOGRAPHY}

In seven patients $M$ mode echocardiograms (Hewlett Packard phased array sector scanner) of the left ventricular cavity were obtained at a level just below the free margins of the mitral valve leaflets where the septum and posterior wall were clearly visible. These images were recorded simultaneously with the left ventricular pressure signal at a paper speed of 100 $\mathrm{mm} / \mathrm{s}$. During these recordings the atrium was paced at a fixed preselected rate (15-20 beats/minute in excess of the control heart rate). The isovolumic indices of left ventricular function were also measured during fixed rate atrial pacing.

\section{DRUG ASSAY}

Serum samples for estimating milrinone concentrations were obtained in seven patients. A high pressure liquid chromatographic assay was used and was performed at the Sterling-Winthrop Research Centre.

\section{STUDY PROTOCOL}

Vasodilator drugs were withdrawn four days before the study. All other regular medications were withheld on the morning of the study. After placement of the catheters the patients were permitted to rest for 15 minutes, and two sets of control haemodynamic measurements were then obtained 20 minutes apart. At the same time blood samples were withdrawn from the coronary sinus and the femoral artery for later 
Table 2 Haemodymamic responses to mibinone in 12 patients with congestive heart failure. Values are mean (SEM)

\begin{tabular}{|c|c|c|c|c|c|c|}
\hline & \multicolumn{2}{|c|}{ Before milrinone $5 \mathrm{mg}$ (min) } & \multicolumn{3}{|c|}{ After milrinone $5 \mathrm{mg}(\min )$} & \multirow{2}{*}{$\stackrel{p}{\text { valuet }}$} \\
\hline & 20 & 0 & 30 & 60 & 90 & \\
\hline $\begin{array}{l}\text { Heart rate }(\text { beats/min) } \\
\text { Cardiac index }\left(1 / \text { min per } \mathrm{m}^{2}\right) \\
\text { Stroke volume index }\left(\mathrm{ml} / \mathrm{beat} \text { per } \mathrm{m}^{2}\right) \\
\text { Systolic blood pressure }(\mathrm{mm} \mathrm{Hg}) \\
\text { Diastolic blood pressure }(\mathrm{mm} \mathrm{Hg}) \\
\text { Mean blood pressure }(\mathrm{mm} \mathrm{Hg}) \\
\text { Systemic vascular resistance }(\mathrm{urits}) \\
\text { Mean right atrial pressure (mm } \mathrm{Hg})(\mathrm{n}=11) \\
\text { Mean pulmonary artery pressure }(\mathrm{mm} \mathrm{Hg})\end{array}$ & $\begin{array}{l}84(5) \\
2 \cdot 4(0 \cdot 2) \\
29(2) \\
139(7) \\
82(2) \\
101(4) \\
23(1) \\
10(2)\end{array}$ & $\begin{array}{l}84(5) \\
2 \cdot 4(0 \cdot 1) \\
29(2) \\
141(7) \\
81(3) \\
102(4) \\
23(1) \\
10(2)\end{array}$ & $\begin{array}{l}87(5) \\
2 \cdot 5(0 \cdot 1) \\
30(1) \\
136(7) \\
79(3) \\
97(4) \\
20(1) \\
8(2)^{\star}\end{array}$ & $\begin{array}{l}90(5)^{\star} \\
2 \cdot 7(0 \cdot 1)^{\star \star} \\
31(2) \\
134(7) \\
77(3) \\
94(4)^{\star} \\
18(1)^{\star \star \star} \\
7(2)^{\star \star \star}\end{array}$ & $\begin{array}{l}89(5) \\
2 \cdot 7(0 \cdot 2)^{\star} \\
31(2) \\
130(7)^{\star \star} \\
78(3) \\
95(5)^{\star} \\
19(2)^{\star \star} \\
8(2)^{\star}\end{array}$ & $\begin{array}{l}<0.01 \\
<0.001 \\
N S \\
<0.01 \\
<0.05 \\
<0.01 \\
<0.001 \\
<0.001\end{array}$ \\
\hline $\begin{array}{l}(n=11) \\
\text { Pulmonary capillary wedge pressure }\end{array}$ & $30(3)$ & $29(3)$ & $23(3)^{\star \star}$ & $22(3)^{\star \star \star}$ & $23(3)^{\star \star \star}$ & $<0.001$ \\
\hline $\begin{array}{l}\text { (mm Hg) }(n=10) \\
\text { Left ventricular end diastolic pressure }(\mathrm{mm} \mathrm{Hg}) \\
\text { Left ventricular max } \mathrm{dP} / \mathrm{dt}(\mathrm{mm} \mathrm{Hg} / \mathrm{s}) \\
\text { Left ventricular } \max \mathrm{dP} / \mathrm{dt} / \mathrm{P}\left(\mathrm{s}^{-1}\right) \\
\text { Left ventricular } \min \mathrm{dP} / \mathrm{dt}(\mathrm{mm} \mathrm{Hg} / \mathrm{s}) \\
\text { Coronary sinus flow (mi/min }(\mathrm{n}=10) \\
\text { Coronary resistance (units) }(\mathrm{n}=10)\end{array}$ & $\begin{array}{l}21(2) \\
19(2) \\
1160(124) \\
22(2) \\
-1096(54) \\
108(12) \\
0.96(0.11)\end{array}$ & $\begin{array}{l}21(2) \\
20(2) \\
1167(119) \\
22(2) \\
-1091(50) \\
106(12) \\
0.98(0.11)\end{array}$ & $\begin{array}{l}13(2)^{\star \star \star} \\
13(2) \star \star \\
1278(150) \\
31(3)^{\star \star \star} \\
-1237(97)^{\star} \\
113(14) \\
0.92(13)\end{array}$ & $\begin{array}{l}10(2)^{\star \star \star} \\
9(2)^{\star \star \star} \\
1283(150)^{\star} \\
37(3)^{\star \star \star} \\
-1238(91)^{\star} \\
125(21) \\
0.86(0.13)\end{array}$ & $\begin{array}{l}10(2)^{\star \star \star} \\
8(2)^{\star \star \star} \\
1228(124) \\
35(3)^{\star \star \star} \\
-1250(88) \star \star \\
136(25) \\
0.83(0-13)\end{array}$ & $\begin{array}{l}<0.001 \\
<0.001 \\
<0.01 \\
<0.001 \\
<0.01 \\
\text { NS } \\
\text { NS }\end{array}$ \\
\hline
\end{tabular}

tOverall significance of changes by analysis of variance; NS, not significant; significance of individual changes with respect to second set of control readings (at $0 \mathrm{~min}$ ): ${ }^{\star} \mathrm{p}<0.05,{ }^{\star \star} \mathrm{p}<0.01,{ }^{\star \star \star} \mathrm{p}<0.001$.
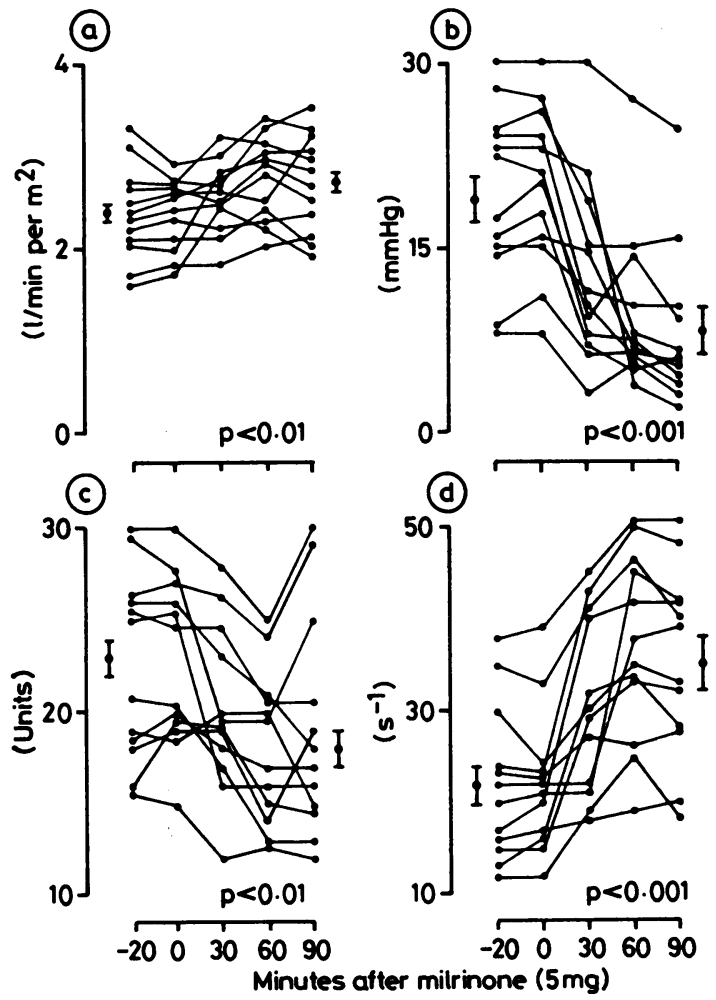

Fig. 1 Effects of milrinone on (a) cardiac index, (b) left ventricular end diastolic pressure, (c) systemic vascular resistance, and (d) left ventricular maximum $d P / d t / P$ in 12 patients. Mean (SEM) values are shown at baseline and 90 minutes after milrinone. biochemical analysis. Milrinone $5 \mathrm{mg}$ was given orally, and haemodynamic measurements and blood sampling were repeated 30,60 , and 90 minutes later. The simultaneous left ventricular echocardiogram and pressure recordings were obtained at the same time intervals but always after the other haemodynamic variables had been measured and the blood samples had been taken.

DATA ANALYSIS

Measurements of stroke volume and vascular resistance (expressed in arbitary units) were derived by standard formulae. Cardiac output and stroke volume were normalised for body surface area. Isovolumic indices of left ventricular function-the rate of rise of pressure $(\mathrm{dP} / \mathrm{dt})$ and the quotient of $\mathrm{dP} / \mathrm{dt}$ and instantaneous pressure $(\mathrm{P})$-were derived by simultaneous analogue processing of the left ventricular pressure signal. The simultaneous records of left ventricular pressure and septal and posterior wall endocardial echoes were digitised between two consecutive $R$ waves on the electrocardiogram using a high resolution $(0.1 \mathrm{~mm})$ digitising tablet (Summagraphics Ltd) interfaced with a microcomputer system (Commodore).

Arterial and coronary sinus blood samples were assayed for whole blood lactate. ${ }^{8}$ Whole blood oxygen and haemoglobin concentrations were measured using a Radiometer OSM2 Hemoximeter; oxygen content was derived by the standard formula. Arteriocoronary sinus concentration differences in whole blood were calculated and the myocardial extraction ratios derived by dividing the arteriocoronary sinus differences by the arterial concentrations expressed as a 
Table 3 Sertom milrinone concentrations. Values are mean $(S E M)(n=7)$

\begin{tabular}{|c|c|c|c|c|c|}
\hline & \multicolumn{2}{|c|}{ Before milrinone $5 \mathrm{mg}$ (min) } & \multicolumn{3}{|c|}{ After milrinone $5 \mathrm{mg}(\mathrm{min})$} \\
\hline & 20 & 0 & 30 & 60 & 90 \\
\hline Serum milrinone concentration $(\mathrm{ng} / \mathrm{ml})$ & ND & ND & $89.3(37.3)$ & $123.9(25.8)$ & $102.5(13 \cdot 2)$ \\
\hline
\end{tabular}

ND, not detectable.

percentage. Myocardial uptake was calculated as the product of arteriocoronary sinus concentration difference in whole blood and coronary sinus flow.

\section{STATISTICAL ANALYSIS}

Two way analysis of variance was used to test the significance of the overall changes in individual haemodynamic and metabolic variables across time. Those variables which changed significantly $(p<0.05)$ were then subjected to a modified $t$ test-using the Bonferroni method-to identify the source of the differences. ${ }^{9}$

\section{Results}

No drug related side effects occurred during the study.

\section{HAEMODYNAMIC RESPONSES}

Table 2 summarises the haemodynamic responses to milrinone and Fig. 1 shows the individual patient data. Table 3 gives the serum milrinone concentrations.

The data in Tables 1 and 2 confirm the severe

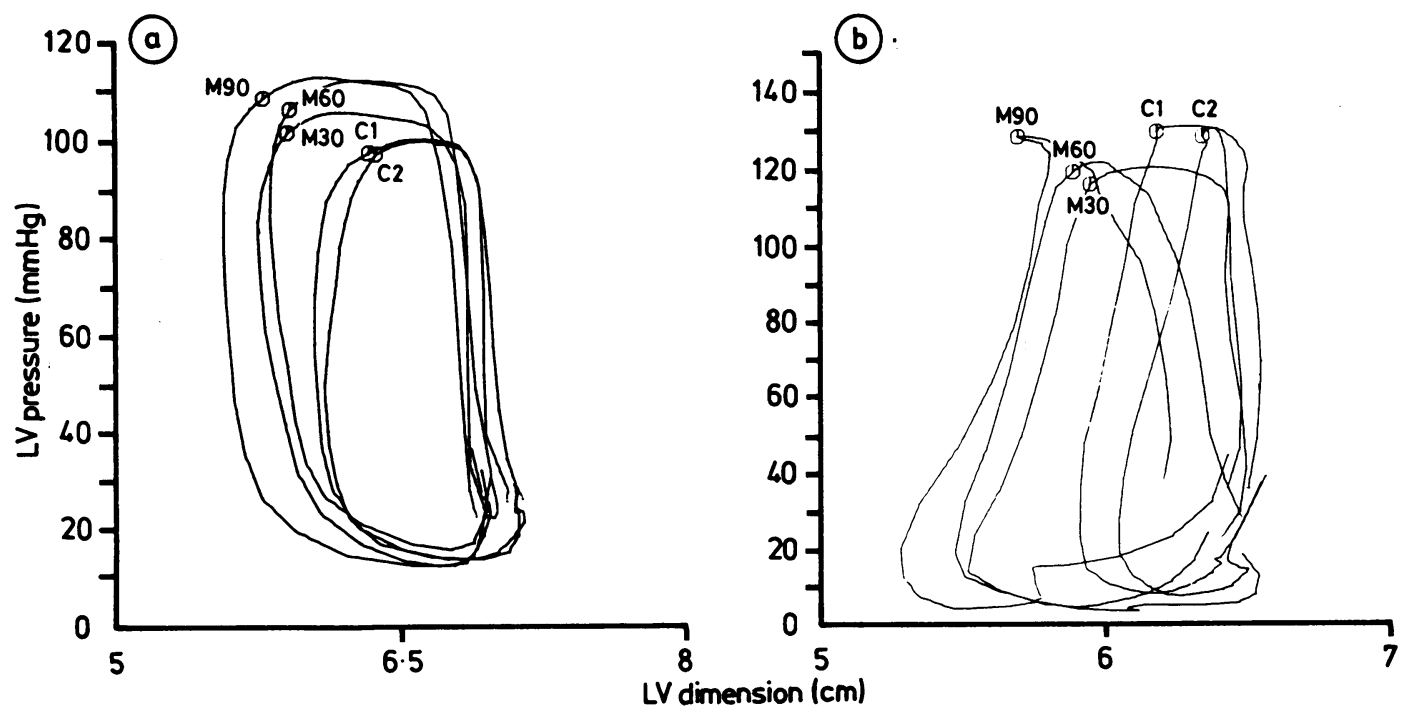

Fig. $2(a)$ and $(b)$. Effects of milrinone on the relation between left ventricular $(L V)$ pressure and dimension in two separate patients. Values before treatment (C1 and C2) and 30,60, and 90 minutes after milrinone (M30, M60, M90) are shown. Open circles indicate the pressure-dimension relation at end systole. baseline left ventricular impairment that characterised this group of patients. Angiographic ejection fraction was depressed, and despite treatment with frusemide both the left ventricular end diastolic pressure and the echocardiographic cavity dimensions were considerably increased (Fig. 2). Cardiac index and stroke volume index, on the other hand, showed variable reductions below the normal range.

Although milrinone produced a prompt reduction in the increased left ventricular filling pressures (as reflected by the changes in left ventricular end diastolic pressure and pulmonary capillary wedge pressure) and a small reduction in right atrial pressure, cardiac index was increased. Stroke volume index, however, did not change significantly because of a small increase in heart rate. Reductions in blood pressure and systemic vascular resistance, though significant, were not pronounced. The isovolumic indices of left ventricular systolic function $(\max \mathrm{dP} / \mathrm{dt}$ and $\max \mathrm{dP} / \mathrm{dt} / \mathrm{P}$ ) both increased, the rise in $\max \mathrm{dP} /$ $\mathrm{dt} / \mathbf{P}$ being particularly prominent. A tendency for coronary sinus flow to increase and for coronary resistance to decline was not significant.

Milrinone produced a leftward shift in the relation 
Table 4 Changes in left ventricular end systolic pressure and dimension. Values are mean $(S E M)(n=7)$

\begin{tabular}{|c|c|c|c|c|c|c|}
\hline \multirow[t]{2}{*}{ Left ventricular end systolic values } & \multicolumn{2}{|c|}{ Before milrinone $5 \mathrm{mg}$ (min) } & \multicolumn{3}{|c|}{ Afier mibrinone $5 \mathrm{mg}$ (min) } & \multirow[t]{2}{*}{$p$ valuet } \\
\hline & 20 & 0 & 30 & 60 & 90 & \\
\hline $\begin{array}{l}\text { Pressure }(\mathrm{mm} \mathrm{Hg}) \\
\text { Dimension }(\mathrm{cm})\end{array}$ & $\begin{array}{l}109(5) \\
6.3(0.3)\end{array}$ & $\begin{array}{l}108(5) \\
6.3(0.3)\end{array}$ & $\begin{array}{l}105(6) \\
6 \cdot 0(0.3)^{\star}\end{array}$ & $\begin{array}{l}102(5) \\
5.9(0.3)^{\star \star}\end{array}$ & $\begin{array}{l}105(6) \\
5.8(0.3)^{\star \star}\end{array}$ & $\begin{array}{l}\text { NS } \\
<0.001\end{array}$ \\
\hline
\end{tabular}

tOverall significance of changes by analysis of variance: NS, not significant; significance of individual changes with respect to second set of control readings (at $0 \mathrm{~min}):{ }^{\star} \mathrm{p}<0.05,{ }^{\star \star} \mathrm{p}<0.01$.

between end systolic pressure and dimension (Fig. 2). The reduction in dimension was significant and was slightly more pronounced than the reduction in pressure (Table 4). In one patient reduction in the left ventricular end systolic cavity dimension occurrred during a progressive increase in pressure (Fig. 2a). More commonly, however, small reductions in end systolic pressure were observed (Fig. 2b).

\section{METABOLIC RESPONSES}

Table 5 summarises the effects of milrinone on oxygen and lactate metabolism. Arterial oxygen saturation and myocardial oxygen extraction remained remarkably constant during the study. Myocardial oxygen uptake, however, tended to increase though the trend was not statistically significant. The arterial concentration of lactate was also unaffected by milrinone, but the myocardial utilisation of this substrate declined; the fall in lactate extraction was significant. No patients showed lactate production during this study.

\section{Discussion}

This study has shown that the acute administration of milrinone to patients with heart failure is well tolerated and leads to a useful improvement in resting left ventricular function. The data indicate that positive inotropism and vasodilatation combine to produce this beneficial effect.

The patients included in this study all had moderate to severe degrees of heart failure caused by coro- nary artery disease or congestive cardiomyopathy. Milrinone produced only a small improvement in cardiac output, but the left ventricular filling pressures fell and in most patients were within the normal range 60-90 minutes after drug administration. This reduction in filling pressures during maintenance of cardiac output must reflect an improvement in left ventricular function.

In studies of this type analysis of the mechanisms responsible for changes in left ventricular function is difficult. The effects of milrinone on the isovolumic indices of left ventricular performance and the relation between end systolic pressure and dimension, however, strongly suggest a positive inotropic response to the drug. The isovolumic indices of ventricular performance provide a measure of contractile function but are also influenced by heart rate and loading conditions. ${ }^{1011}$ In the present study the changes in loading that occurred in response to milrinone would have tended to reduce left ventricular $\max \mathrm{dP} / \mathrm{dt} .{ }^{10}$ Because atrial pacing controlled for changes in heart rate, the increase in left ventricular $\max \mathrm{dP} / \mathrm{dt}$ during the study is best explained by an increase in contractility. Left ventricular $\max \mathrm{dP} / \mathrm{dt} / \mathrm{P}$ is less susceptible to the influence of loading conditions, ${ }^{11}$ and the drug induced improvement in this measure of contractile function strengthens the conclusion that positive inotropism contributed towards the beneficial effects of milrinone.

The leftward displacement of the relation between left ventricular end systolic pressure and dimension that occurred in response to milrinone was due to a

Table 5 Metabolic responses to milrinone in eight patients with congestive heart failure. Values are mean (SEM)

\begin{tabular}{|c|c|c|c|c|c|c|}
\hline & \multicolumn{2}{|c|}{ Before milrinone $5 \mathrm{mg}$ ( $\mathrm{min}$ ) } & \multicolumn{3}{|c|}{ After milrinone 5 mg (min) } & \multirow[t]{2}{*}{ p valuet } \\
\hline & 20 & 0 & 30 & 60 & 90 & \\
\hline $\begin{array}{l}\text { Oxygen: } \\
\text { Arterial saturation }(\%) \\
\text { Myocardial extraction }(\%) \\
\text { Myocardial uptake }(\mathrm{ml} / \mathrm{min}) \\
\text { Lactate: } \\
\text { Arterial concentration }(\mathrm{mmol} / /) \\
\text { Myocardial extraction }(\%) \\
\text { Myocardial uptake }(\mu \mathrm{mol} / \mathrm{min})\end{array}$ & $\begin{array}{r}96.4(0.5) \\
64.7(2.0) \\
13.9(2.0) \\
\\
1.1(0.1) \\
29.5(5.2) \\
35.0(7.0)\end{array}$ & $\begin{array}{r}96.5(0.9) \\
63.3(2.5) \\
13.3(1.7) \\
\\
1.0(0.1) \\
29.7(5.4) \\
33.9(6.8)\end{array}$ & $\begin{array}{c}97.0(0.8) \\
63.8(2.5) \\
14.5(2.4) \\
\\
1.0(0.1) \\
23.5(6.9) \\
30.8(10.4)\end{array}$ & $\begin{array}{c}96.4(0.8) \\
63.8(2.4) \\
16.0(3.2) \\
\\
1.0(0.1) \\
21.9(6.5) \\
34.1(12.5)\end{array}$ & $\begin{array}{c}95.0(0.9) \\
63.3(2.2) \\
18.2(4.1) \\
\\
1.0(0.1) \\
16.4(5.3))^{\star \star \star} \\
25.9(9.1)\end{array}$ & $\begin{array}{l}\text { NS } \\
\text { NS } \\
\text { NS } \\
\text { NS } \\
<0.001 \\
\text { NS }\end{array}$ \\
\hline
\end{tabular}

tOverall significance of changes by analysis of variance: NS, not significant; significance of individual changes with respect to second set of control readings (at $0 \mathrm{~min}$ ): ${ }^{\star \star \star} \mathrm{p}<0.001$. 
significant reduction in cavity dimension. The reduction in end systolic pressure was not significant (unlike the change in peak systolic pressure measured in larger numbers of patients). Indeed in one case left ventricular pressure increased during simultaneous reductions in cavity dimension. Though we have previously emphasised the caution that is necessary in interpreting data of this type ${ }^{12}$ (extrapolation from pressure-volume relations in the normal heart to pressure-dimension relations in the failing heart has not, as yet, been validated experimentally ${ }^{13}$ ) the reduction in end systolic dimension without pronounced alteration in end systolic pressure suggests a positive inotropic response to the drug. ${ }^{14}$ The response to milrinone should be contrasted with the response to felodipine-a potent vasodilator-which produces a pronounced downward displacement in the relation between the end systolic pressure and dimension in patients with heart failure. ${ }^{12}$

The useful reduction in left ventricular filling pressures that occurred during this study is explained in part by the effects of milrinone on diastolic ventricular function. Preliminary work has shown that this drug improves indices of left ventricular diastolic relaxation and chamber distensibility in patients with heart failure. ${ }^{15}$ Our finding of a significant increase in left ventricular min $\mathrm{dP} / \mathrm{dt}$ supports this observation. Associated systemic venous pooling, however, is likely to have contributed to the reduction in ventricular filling pressures, and the small reductions in blood pressure and systemic vascular resistance point to associated arteriolar dilatation. Vasodilatation, therefore, appears to make an important contribution to the beneficial haemodynamic effects of milrinone as indicated by the data of Cody et al. ${ }^{16}$

The metabolic consequence of antifailure treatment is an important consideration in the assessment of new agents. Milrinone produced a small increase in heart rate in addition to enhancing contractility. Increments in myocardial oxygen demand, however, were to some extent offset by associated reductions in wall tension caused by diminished left ventricular cavity dimensions and vasodilatation. ${ }^{17}$ Thus myocardial oxygen consumption and lactate production did not change significantly. Both variables, however, tended to increase and the associated rise in myocardial lactate extraction was statistically significant. Though the determinants of lactate extraction are complex, ${ }^{18}$ our data do not exclude an adverse effect on myocardial ischaemia: further work is necessary to evaluate this issue.

The beneficial haemodynamic effects of milrinone in congestive heart failure are confirmed in the present study. The drug, which is well tolerated, improves left ventricular systolic function as a result of simultaneous positive inotropism and vasodilata- tion. The combination of these separate cardiovascular influences to some extent protects against myocardial ischaemia. The changes that occurred in oxygen and lactate metabolism, however, although not statistically significant, suggest the need for caution in the use of milrinone in patients with severe coronary artery disease.

\section{References}

1 Alousi AA, Canter JM, Montenaro MJ, Fort DJ, Ferrari RA. Cardiotonic activity of milrinone, a new and potent cardiac bipyridine, on the normal and failing heart of experimental animals. I Cardiovasc Pharmacol 1983; 5: 792-803.

2 Alousi AA, Stankus GP, Stuart JC, Walton LH. Characterization of the cardiotonic effects of milrinone, a new and potent cardiac bipyridine, on isolated tissues from several animal species. f Cardiouasc Pharmacol 1983; 5: 804-11.

3 Sinoway LS, Maskin CS, Chadwick B, Forman R, Sonnenblick EH, Le Jemtel TH. Long-term therapy with a new cardiotonic agent, WIN 47203: drug-dependent improvement in cardiac performance and progression of the underlying disease. $f \mathrm{Am} \mathrm{Coll}$ Cardiol 1983; 2: 327-31.

4 Maskin CS, Sinoway L, Chadwick B, Sonnenblick EH, Le Jemtel TH. Sustained hemodynamic and clinical effects of a new cardiotonic agent, WIN 47203, in patients with severe congestive heart failure. Circulation 1983; 67: 1065-70.

5 Baim DS, McDowell AV, Cherniles J, et al. Evaluation of a new bipyridine inotropic agent-milrinone-in patients with severe congestive heart failure. $N$ Engl f Med 1983; 309: 748-56.

6 Miller RR, Palomo AR, Brandon TA, Hartley CJ, Quinones MA. Combined vasodilator and inotropic therapy of heart failure: experimental and clinical concepts. Am Heart f 1981; 102: 500-8.

7 Ganz W, Tamura K, Marcus HS, Donoso. R, Yoshida S, Swan HJC. Measurement of coronary sinus blood flow by continuous thermodilution in man. Circulation 1971; 44: 181-95.

8 Livesley B, Atkinson L. Accurate quantitative estimation of lactate in whole blood [Letter]. Clin Chem 1974; $20: 1478$.

9 Wallenstein S, Zucker CL, Fleiss JL. Some statistical methods useful in circulation research. Circ Res 1980; 47: 1-9.

10 Wallace AG, Skinner NS Jr, Mitchell JH. Hemodynamic determinants of the maximal rate of rise of left ventricular pressure. Am f Physiol 1963; 205: 30-6.

11 Mason DT, Braunwald E, Covell JW, Sonnenblick EH, Ross J Jr. Assessment of cardiac contractility. The relation between the rate of pressure rise and ventricular pressure during isovolumic systole. Circulation 1971; 44: 47-58.

12 Timmis AD, Campbell S, Monaghan MJ, Walker L, Jewitt DE. Acute haemodynamic and metabolic effects of felodipine in congestive heart failure. Br Hear $\mathcal{F}$ 1984; 51: 445-51.

13 Sagawa K. The ventricular pressure-volume diagram revisited. Circ Res 1978; 43: 677-87.

14 Borow KM, Neumann A, Wynne J. Sensitivity of end-systolic pressure-dimension and pressure-volume relations to the inotropic state in humans. Circulation 1982; 65: 988-97.

15 Monrad ES, McKay RG, Baim DS, McDowell AV, Heller G, Grossman W. Does milrinone improve diastolic ventricular function in congestive heart failure? [Abstract]. Circulation 1983; 68 (suppl III): 102.

16 Cody RJ, Kubo SH, Müller FB, Rutman H, Leonard D. Vasodilator properties of milrinone: an intra-arterial study [Abstract]. Circulation 1984; 70 (suppl II): 11.

17 Braunwald E. Control of myocardial oxygen consumption. Physiologic and clinical considerations. Am f Cardiol 1971; 27: 416-32.

18 Gertz EW, Wisneski JA, Neese R, Houser A, Korte R, Bristow JD. Myocardial lactate extraction: multi-determined metabolic function. Circulation 1980; 61: 256-61. 